\section{What Opportunities are there at COP21 for Advancing the Understanding of the Impact of Climate Change on Public Health?}

Received: November 16, 2015, Accepted: November 17, 2015, Published: November 20, 2015

The 2009 UCL-Lancet Commission stated that "climate change is the biggest global health threat of the 21st century". The effects of climate change are already felt today and will be felt everywhere with an unacceptably high and potentially catastrophic risk to mankind existence. Records show that average temperatures climbing. Y2014 was the warmest year since modern record keeping began, according to the US National Aeronautics and Space Administration (NASA) [1]. Overall, the Earth (global average land and ocean temperatures) has warmed by some $0.85^{\circ} \mathrm{C}$ between 1880 and 2012 [2]. Arctic sea ice is disappearing at a rate of up to $50,000 \mathrm{~km}^{2}$ per year, and the Antarctic ice sheet is now losing 159 billion tons of ice each year, therefore sea levels are rising inexorably [3].

Maintaining the global average temperature rise to less than $2^{\circ} \mathrm{C}$ per year is extremely important in order to avoid the risk of potentially catastrophic climate change impacts, whereas projection scenarios show global average warming of $2.6-4.8^{\circ} \mathrm{C}$ by the end of 21 century, if the situation will not change.

It is required that total anthropogenic carbon dioxide $\left(\mathrm{CO}_{2}\right)$ emissions to be kept below 2900 billion tones $\left(\mathrm{GtCO}_{2}\right)$ by the end of the century. However, records shows that total emissions since 1870 were a little over half of this, with current trends expected to exceed $2900 \mathrm{GtCO}_{2}$ in the next $15-30$ years [4].

The climate change poses a range of threats to human health. An increase of more than 2 degrees Celsius in average temperature would result in negative health impacts in all geographical regions. Impacts can be indirect to human health, such as effects on agriculture, disease appearance as well as to economics or even social life. The direct effects of climate change include increased heat stress, floods, drought, and increased frequency of intense storms, with the indirect threatening population health through adverse changes in air pollution, the spread of disease vectors, food insecurity and under-nutrition [4]. The health impacts of climate change include increases in heat-related illnesses and death; extreme weather-related injuries and mortality; aggravated chronic illnesses; spread of infectious diseases: vector-, zoonotic-, water-and food-borne diseases; increases in asthma, respiratory allergies, and chronic respiratory disorders; growing malnutrition and child development complications; increases in stress-related and mental health disorders; growing health impacts related to

\section{Indre Butiene}

Vice dean for development and international affairs, Faculty of Health Science, Klaipeda University, Lithuania

Corresponding author: Indre Butiene

\section{indre.butiene@ku.it}

Vice dean for development and international affairs, Faculty of Health Science, Klaipeda University, Lithuania.

Tel: 37068555305

Citation: Butiene I. What Opportunities are there at COP21 for Advancing the Understanding of the Impact of Climate Change on Public Health? Insights Allergy Asthma Bronchitis. 2015, 1:2.

both population displacement and migration; as well as climatetriggered instability and conflicts.

The health care specialist's community is just beginning to understand that climate change will have major impacts on health care costs, services and delivery. Health care professionals are working against health threats, such as tobacco, HIV/ AIDS, poliomyelitis, and have often confronted powerful entrenched interests in doing so. Likewise, they must be leaders in responding to the health threat of climate change. A public health perspective has the potential to consolidate all actors behind a common cause-the health and wellbeing of families, communities and countries. These concepts are far more tangible and visceral than tones of atmospheric $\mathrm{CO}_{2}$, and are understood and prioritized across all populations irrespective of their cultural or development status.

Some population groups, such as young children and older people, people with chronic diseases or disabilities, poor and marginalized communities, are particularly vulnerable to the health effects of climate change. Such inequalities are often also present in relation to the causes of climate change: both women and children suffer from the health impacts of indoor air pollution from inefficient cookstoves and kerosene lighting, and so 
mitigation measures can help to reduce existing health inequities such as these [4]. Rigorous epidemiological research carried out by the WHO has demonstrated that even the relatively modest warming seen between 1970 and 2004 resulted in detectable effects on human health, with an estimated 140,000 extra deaths per year attributable to climate change at this time. The more recent analysis suggests that as many as 400,000 deaths are attributable to climate change in 2010, with a significant increase in this figure expected by 2030. In this regard, climate change acts as a 'force multiplier', exacerbating many of the world's global health challenges.

The future burden and costs of the impact on public health resulting from climate change are challenging to measure. However, many policies aimed at combating climate change have indirect benefits for health aside from the direct benefits that avoiding global warming would bring. For example, 'active transport' where people walk or cycle more and use their cars less, reduces greenhouse gas emissions and leads to reductions in cardiovascular disease and cancer through improved fitness. Cleaner sources of energy use in industry and transport reduce greenhouse gas emissions and reduce the levels of certain other air pollutants. Cleaner air benefits everyone's health and especially those with asthma or other respiratory or cardiac conditions [5]

The cost savings of the health co-benefits achieved by policies to cut GHG emissions are potentially large. This is particularly important in a context where health-care expenditure is growing relative to total government expenditure globally. The health dividend on savings must be factored into any economic assessment of the costs of mitigation and adaptation. The poorest people are also most vulnerable to climate change, meaning that the costs of global development will rise if we do nothing, and poverty alleviation and sustainable development goals will not be achieved [4].

The analysis makes the case for the European Union stepping up its current 20\% target in greenhouse gas emissions by 2020 (from 1990 levels) to a $30 \%$ domestic target. It shows additional health benefits beyond $20 \%$ estimated at between $€ 10.5$ billion and $€ 30.5$ billion per year by 2020 by commitment to the extra mitigation effort. This is equivalent to between $€ 21$ and $€ 60$-worth of health savings for each person in the EU27 countries per year in 2020. The upper estimate of the health benefits at $€ 30.5$ billion per year in 2020 is equivalent to roughly two-thirds of the European Commission's own estimate of the implementation costs of the internal 30\% target. The Commission puts the additional cost at $€ 46$ billion per year in 2020, equivalent to $0.3 \%$ of GDP [5].

The international political response to climate change began at the Rio Earth Summit in 1992, where the 'Rio Convention' included the adoption of the UN Framework on Climate Change (UNFCCC). This convention set out a framework for action aimed at stabilizing atmospheric concentrations of greenhouse gases (GHGs) to avoid "dangerous anthropogenic interference with the climate system." The UNFCCC which entered into force on 21 March 1994, now has a near-universal membership of 195 parties.

The main objective of the annual Conference of Parties (COP) is to review the Convention's implementation. The first COP took place in Berlin in 1995 and significant meetings since then have included COP3 where the Kyoto Protocol was adopted, COP11 where the Montreal Action Plan was produced, COP15 in Copenhagen where an agreement to success Kyoto Protocol was unfortunately not realized and COP17 in Durban where the Green Climate Fund was created.

France will chair and host the 21st Conference of the Parties to the United Nations Framework Convention on Climate Change (COP21/CMP11), from 30 November to 11 December 2015 [6]. COP21 will, for the first time in over 20 years of UN negotiations, aim to achieve a legally binding and universal agreement on climate, with the aim of keeping global warming below $2^{\circ} \mathrm{C}$. France will play a leading international role in hosting this seminal conference, and COP21 will be one of the largest international conferences ever held in the country. The conference is expected to attract close to 50,000 participants including 25,000 official delegates from government, intergovernmental organizations, UN agencies, NGOs and civil society. 


\section{References}

1 Climate Change: Climate Resource Center-Ten coldest and warmest years.

2 Ipcc. Climate Change (2013) The Physical Science Basis. Contribution of Working Group I to the Fifth Assessment Report of the Intergovernmental Panel on Climate Change. Intergov Panel Clim Chang Work Gr I Contrib to IPCC Fifth Assess Rep (AR5)(Cambridge Univ Press New York) pp:1535.

3 McMillan M, Shepherd A, Sundal A, Briggs K, Muir A, et al. (2014)
Increased ice losses from Antarctica detected by CryoSat-2. Geophys Res Lett 41:3899-905.

4 Watts N, Adger WN, Agnolucci P, Blackstock J, Byass P et al. (2015) Health and climate change: policy responses to protect public health. Lancet 6736: 53.

5 Jensen G (2010) Executive Director H and EA (HEAL), Anja Leetz, Executive Director HCHE (HCWH E. Acting now for better health. Primerveraquint pp:1-40.

6 UNFCCC COP 21 Paris France - 2015 Paris Climate Conference. 